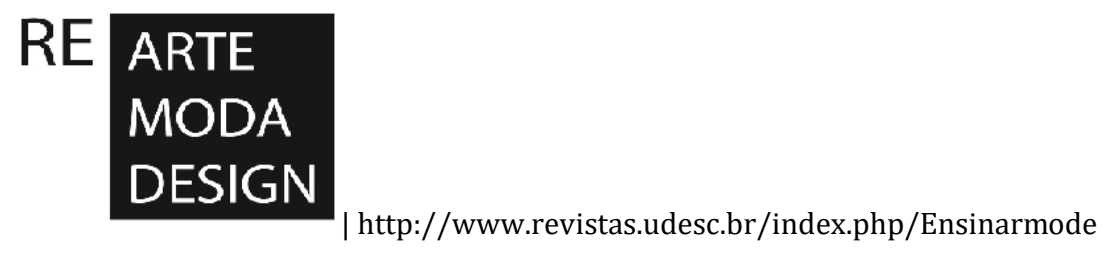

\title{
ENSINO DE SEMIÓTICA APLICADA ATRAVÉS DA APRENDIZAGEM BASEADA EM PROJETOS (PjBL): UMA PROPOSTA METODOLÓGICA
}

\author{
Teaching of semiotics applied by Project-Based Learning (PjBL): \\ a methodological proposal
}

Lucia Teresinha Peixe Maziero ${ }^{1}$

\section{RESUMO}

Este artigo discute a aprendizagem baseada em projetos - PjBL (Project-Based Learning), que se desenvolve sob o processo de obtenção de um produto final, a qual foi utilizada como metodologia norteadora da disciplina de semiótica aplicada no curso de Design de Moda. Apresentam-se aqui as ações de ensino por meio de aprendizagem ativa que levaram os estudantes à formulação do problema de pesquisa, às análises e resultados, e a escrita de um artigo com potencial de publicação científica. Como objeto de estudo para a pesquisa foram analisadas publicidades de joias, veiculadas em revista de moda, analisadas por meio de duas vertentes semióticas: Peirce e Greimas.

Palavras-chaves: Ensino. Semiótica. Moda. Aprendizagem Ativa.

\begin{abstract}
This article discusses project-based learning (PjBL), which developed under the process of obtaining an ended product. It was use as a guiding methodology for the discipline of applied semiotics, in the course of Fashion Design. Here we present the teaching actions through active learning that led the students to formulate the research problem, the analysis and results, and the writing of the article with the potential of scientific publication. As an object of study for the research were, analyzed advertising of jewelry, published in a fashion magazine, analyzed through two semiotic aspects: Peirce and Greimas.
\end{abstract}

Keywords: Teaching. Semiotics. Fashion. Active Learning.

\footnotetext{
${ }^{1}$ Doutora. Professora Titular na Escola de Arquitetura e Design da Pontifícia Universidade Católica do Paraná - PUCPR (desde 1999) nos cursos de Arquitetura e Urbanismo e nos cursos de Design, atuando no ensino e pesquisa nas áreas de Semiótica e Cartografias Urbanas. Atua no curso de Especialização em Paisagismo: Planejamento e Projeto na PUCPR (desde 2010). Líder do grupo de pesquisa Comunicação na Arquitetura e Design.

E-mail: lucia.maziero@gmail.com Lattes: http://lattes.cnpq.br/4784142572813923
}

Revista ENSINARMODE, Florianópolis, Vol. 2, N. 1, Fevereiro-Maio 2018, p. 057-076. DOI: http://dx.doi.org/10.5965/25944630212018057 | ISSN 2594-4630 


\section{RE ARTE \\ MODA \\ DESIGN \\ http://www.revistas.udesc.br/index.php/Ensinarmode}

\section{INTRODUÇÃO}

Este artigo busca retratar as ações, e análises de seus resultados, sobre a introdução de aprendizagem ativa, particularmente a Aprendizagem por Projetos PjBL, do termo em inglês Project-Based Learning, na prática de uma disciplina com base em seus conceitos teóricos - a Semiótica, com o intuito de contribuir para o conhecimento que gera melhorias no ensino voltado à inovação.

A busca por novos meios de ensino é decorrente das mudanças na atuação dos indivíduos na sociedade, para as quais surge a necessidade de uma nova posição no ensino envolvendo discentes e docentes. Esses, por muito tempo assumiram por um lado o papel de transmissor de conhecimento, enquanto que 0 outro permanecia em atitude passiva, receptiva e reprodutora, atuando como expectador, sem maior preocupação com a crítica e reflexão (BEHRENS, 2011).

Logo, no que se refere ao ensino para atender aos novos perfis de indivíduos e de futuros profissionais, busca-se uma reorganização metodológica para aumentar a qualidade da aprendizagem. Tal transformação requer novos sujeitos no papel desses indivíduos, tais como um discente ativo e reflexivo, para tornar-se autônomo, responsável e capaz de atualizar suas potencialidades, de modo criativo e indagador do conhecimento em uma realidade que é permanentemente mutável. Enquanto isso, o docente passa a ser um intermediador do processo, oferecendo oportunidades para que isso aconteça (SCALLON, 2015).

Esse estudo vem de encontro às transformações que a sociedade contemporânea vem passando, buscando determinar influências sobre os aspectos relativos à atuação do indivíduo, tanto no âmbito pessoal, como em sua formação e na atividade profissional. Nessas três instâncias, a universidade tem papel fundamental, que é o de aliar conhecimento - o saber, o saber - ser e o saber - agir, por meio de seus processos de ensino e aprendizagem (SCALLON, 2015).

No que se refere ao ensino, os cursos de graduação da PUCPR têm sido estimulados a incluírem novas propostas em suas reorganizações metodológicas, para atender aos novos perfis delineados para os seus estudantes, futuros profissionais (PUCPR, 2017). Em particular, nesta proposta, discute-se uma disciplina teórica, a Semiótica, em abordagens de aplicação na prática. Essa 


\section{RE ARTE \\ MODA \\ DESIGN}

demanda vem sendo sistematizada nos cursos de graduação da Escola de Arquitetura e Design da PUCPR, os quais possuem matrizes curriculares que, atendendo às diretrizes nacionais de ensino, contemplam conteúdos básicos e complementares à formação de profissionais com habilidades e competências específicas.

Em sua aplicação prática, a proposta de Aprendizagem por Projetos (PjBL), definida por Lou et al. (2012), adota como princípio o papel ativo dos estudantes na construção do conhecimento. Nessa concepção, a aprendizagem ocorre durante o processo de desenvolvimento de um projeto. Uma característica dessa concepção é que a responsabilidade da aprendizagem passa a ser do estudante, que deve assumir um papel ativo, tendo o professor como seu orientador.

Sob esse aspecto, essa metodologia ( $\mathrm{PjBL}$ ) foi aplicada na disciplina de Semiótica Aplicada, do Curso Design de Moda na PUCPR. Na proposta, foi definido um projeto norteador da aprendizagem para ocorrer durante todo o período semestral, o qual envolveria desde a formulação da questão de pesquisa, a realização da pesquisa em si, a análise de seus resultados, e o desenvolvimento de seu produto final, que nesse caso seria a realização de um artigo científico.

Desse modo, apresentam-se aqui as ações de ensino por meio de aprendizagem ativa, que levaram os estudantes a obtenção do produto: artigo científico com potencial para publicação, e as análises decorrentes desse modo de ensino. Como objeto de estudo para a pesquisa foram analisadas publicidades de joias, veiculadas em revista de moda, analisada por meio de duas vertentes semióticas: Peirce e Greimas.

\section{CONSTRUÇÃO DE UM PLANO DE ENSINO}

A disciplina para essa análise foi Semiótica Aplicada, do 5ำ período do curso Design de Moda da PUCPR, que foi planejada para ser realizada por meio da aprendizagem ativa, no primeiro semestre de 2017. Seu eixo condutor seria a aprendizagem por projeto $(\mathrm{PjBL})$, porém, contemplando também, outras abordagens necessárias para permearem o processo. 


\section{RE ARTE \\ MODA \\ DESIGN}

| http://www.revistas.udesc.br/index.php/Ensinarmode

$\mathrm{Na}$ disciplina seriam contemplados os conceitos básicos das teorias de Greimas e Peirce, já abordados na disciplina de introdução à semiótica no semestre anterior. Como tal, os estudantes poderiam aplicar esses conceitos, já aprendidos, para além de um trabalho didático, que foi o propósito da presente pesquisa, de se obter um produto como resultado de um projeto, que, no caso, seria a escrita de um artigo científico.

A importância de se escrever um artigo científico está na possibilidade de se reconhecer a constituição de uma área de conhecimento e os limites e avanços em relação às abordagens da mesma. Além de ser necessário realizar uma pesquisa aplicada como constituição de base do mesmo (LAKATOS; MARCONI, 2011).

Logo, esse foi o produto proposto no projeto da disciplina: escrever um artigo científico com base em metodologias de análise semiótica, aplicadas sobre um tema relacionado a moda, caracterizada em um recorte espacial e temporal, com possibilidade de publicação em evento da área.

\subsection{Aprendizagem Ativa}

Um conceito de aprendizagem ativa é estabelecido por Scallon (2015), que envolve tanto as abordagens temáticas como a postura do estudante e do professor frente às mesmas. Nesse modelo, as temáticas devem tratar de situações e expectativas de desempenho, da autenticidade das mesmas, da interatividade, da aprendizagem multidimensional, do julgamento explícito e de auto avaliação. Enquanto que o estudante passa a ser o protagonista do seu estudo, e o professor como orientador, das suas descobertas para o conhecimento. No entanto, o papel do professor abrange também a tomada de decisões frente à cada situação, que em geral, pode nem ter sido planejada.

O processo que envolve a aprendizagem ativa deve guiar o estudante para a sua atividade profissional. Nesse sentido, Mitre et al. (2008) lembram que a graduação dura somente alguns anos, enquanto a atividade profissional pode permanecer por toda uma vida, e, nela, conhecimentos e competências devem se transformar. Logo, entende-se que as práticas metodológicas de ensino e de 


\section{RE ARTE \\ MODA \\ DESIGN}

aprendizagem ativa propiciam a formação de um profissional apto a aprender e pesquisar continuadamente.

Para Felder e Brent (2009), a aprendizagem ativa possibilita tratar com o estudante situações de conhecimento, de habilidades e de competências. Nela, o estudante é colocado como agente do processo de aprendizado, principalmente no sentido de tornar-se autônomo. Nesse modelo de aprendizagem os estudantes são desafiados a buscarem respostas para problemas, individualmente, e em grupo.

Assim, na área da educação, bem como em áreas específicas, encontram-se várias metodologias, técnicas e instrumentos que propiciam o aprendizado ativo. Entre os principais meios, tem-se a aprendizagem baseada em projeto, a aprendizagem baseada em problemas ou estudo de caso, a aprendizagem colaborativa, cooperativa, reflexiva e por pesquisa.

Lou et al. (2012) apresentam a aprendizagem baseada em projetos - PjBL (Project-Based Learning), na qual há sempre um produto final como resultado. O estudo parte de um contexto em que elementos para a solução se apresentam de forma aberta. As atividades geralmente definem o processo e o estudante tem participação ativa na solução do problema. A avaliação dessa aprendizagem deve ser realizada sobre o processo e também o resultado.

A aprendizagem por problemas - PBL (Learning Problem) e aprendizagem por estudo de caso (Learning Case-Based) apresentam procedimentos semelhantes. Entretanto, quando um problema se apresenta definido, esse consiste em um estudo de caso (KOPP et al., 2009). Para esses modelos de aprendizagem, parte-se de um contexto com uma problemática, que origina questões, para as quais deve-se pesquisar para propor a solução. O estudo de caso demanda um conhecimento anterior e visa a interpretação do caso à luz de questões propostas. O PBL abrange vários conteúdos, cabendo aos estudantes a definição sobre o que servirá para a solução do problema, sem propor um produto final. Para o estudo de caso, o estudante dispõe de informações para a solução dos problemas, diferenciando-se do PBL.

Há várias outras situações de aprendizagem ativa, tais como a colaborativa (Collaborative Learning) e a cooperativa (Cooperative Learning), apresentadas em Panitz (2009); reflexiva (Reflective Learning) discutida em Brockbank, McGill and 


\section{RE ARTE \\ MODA \\ DESIGN}

Beech (2002); por pesquisa (Inquiry-Based Learning) apresentada em Justice et al. (2009). Por fim, quando a aprendizagem possibilita atividades em ambiente presencial e à distância, ela é chamada de híbrida (Learning Blended). Esse modelo de aprendizagem possibilita maior adequação ao contexto e as atividades são coerentes e conexas ao que se pretende que o estudante aprenda. Dentre essas, destacam-se ainda, a sala de aula invertida (Flipped Class), apresentada em Hamdan et al. (2013), e a aprendizagem por pares (Peer Instruction), criada por Mazur (1997).

Um importante modo de ensino/aprendizagem, pode ser obtido com a sala de aula invertida (Flipped Class), onde a aprendizagem é centrada no estudante, para o qual o conteúdo é propiciado anteriormente. Com posse desse, o estudante pode acessar quantas vezes forem necessárias para sua compreensão. O conteúdo disponibilizado antes pode ser em formato de texto, de vídeo ou de áudio, de modo que o estudante possa acessá-lo de qualquer lugar e em qualquer tempo para conhecê-lo. Nesse modelo de metodologia, o tempo em sala de aula passa a ser utilizado com o professor em atividades que engajem os estudantes ativamente, como na realização de projetos, aprendizagem por pares, trabalhos em grupos, entre outros (HAMDAN et al., 2013).

A aprendizagem por pares (Peer Instruction) possibilita a realização de atividades de interação. Em geral, a aprendizagem se inicia com o estudo prévio de materiais disponibilizados pelo professor e na sala de aula, conceitos fundamentais dos conteúdos são primeiramente respondidos individualmente e depois discutidos em grupo. Assim, o momento na sala de aula consiste em atividades de interação entre os estudantes para completar a aprendizagem. Nesse modelo, a troca ativa de informações entre os pares propicia o aproveitamento das competências dos membros do grupo para a integral compreensão dos conceitos (MAZUR, 1997).

Nesse caminho, o Creare (2016) - Centro de Ensino e Aprendizagem, criado na PUCPR para apoiar ações relacionadas ao ensino -, apresenta como condições para a aprendizagem ativa, que as disciplinas proporcionem motivação-significativa para o estudante; coloquem o aluno permanentemente ativo e reflexivo, tanto individualmente como com seus pares; ofereçam meios para colaboração mútua entre os estudantes; e, propiciem a associação à ação e prática da realidade 


\section{RE ARTE \\ MODA \\ DESIGN}

profissional. Além dessas condições, deve haver o alinhamento entre competências e habilidades, estratégias e/ou atividades, produtos, e/ou resultado esperado, e suas avaliações.

\subsection{Design da disciplina}

A proposta da disciplina compreenderia no primeiro bimestre a realização de uma pesquisa, e, com seus resultados, no segundo bimestre, a escrita de um artigo. Todo esse processo seria desencadeado pelos estudantes na abordagem ativa: a formulação da questão de pesquisa, a realização da pesquisa em si, a análise de seus resultados e a escrita do artigo.

Coube ao professor estruturar a disciplina para desencadear junto aos estudantes todo o processo. Assim, a estrutura base do primeiro bimestre, realizada em nove semanas de aulas, foi a apresentada na Figura 1. Esta foi organizada para atender os resultados de aprendizagem esperados, contendo as competências, habilidades e conteúdo a serem trabalhados, dispostos nessa figura, em uma linha do tempo.

Figura 1: Mapa do Plano de Ensino.

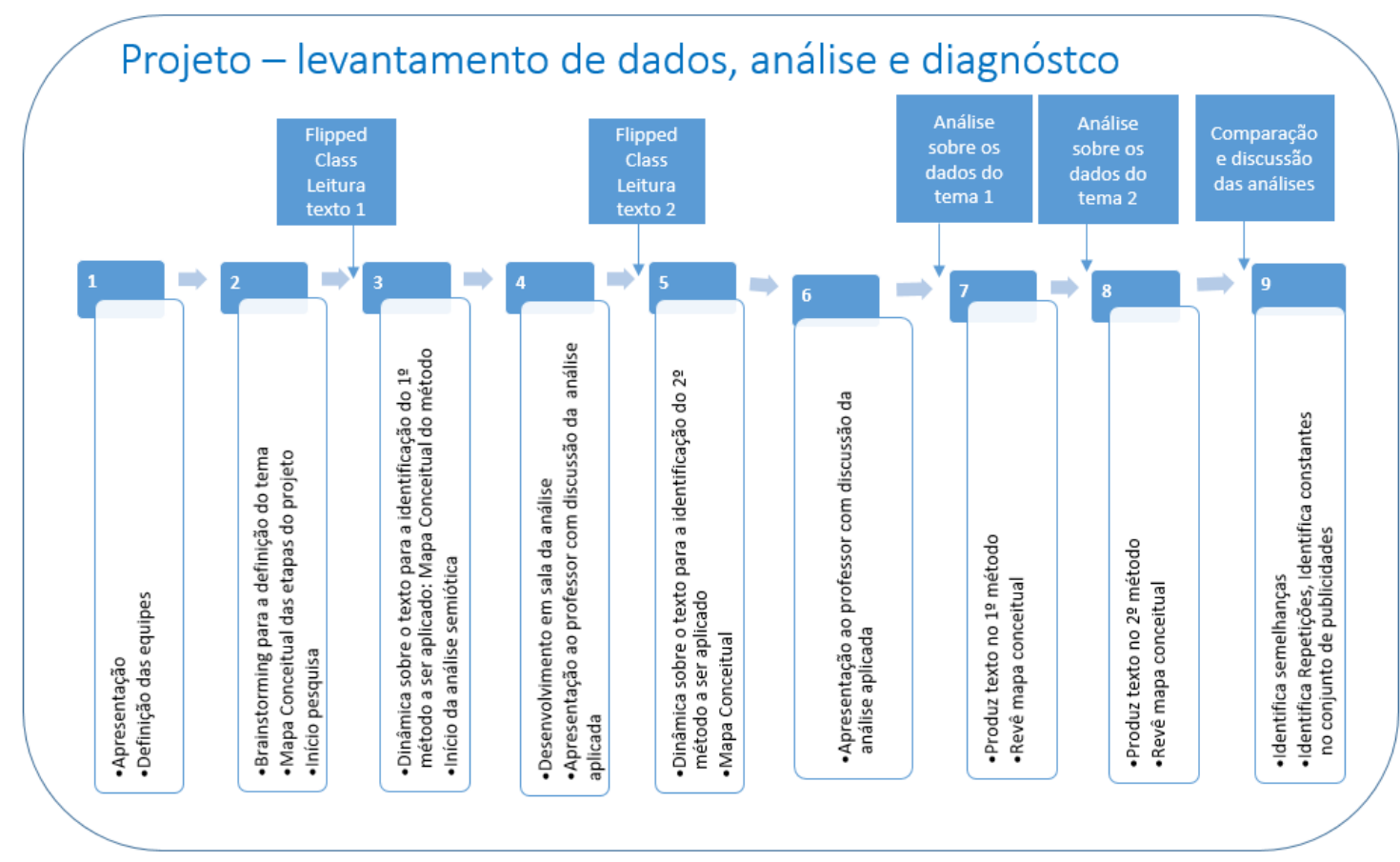

Fonte: A Autora 


\section{RE ARTE \\ MODA \\ DESIGN}

| http://www.revistas.udesc.br/index.php/Ensinarmode

Essa proposta foi apresentada para a turma, e, com a participação da mesma, foi orientado o encaminhamento das atividades, resultados e avaliações a serem descritos no Plano de Ensino.

\section{DESENVOLVIMENTO DAS AULAS}

Como colocado acima, a construção do plano de ensino também foi uma ação de aprendizagem ativa. Os estudantes participaram de sua construção inicial por meio de suas ações e análises críticas.

Assim, na Aula 1, como primeiro encontro (de duas horas/aulas), foi apresentado aos estudantes a proposta. Metodologicamente, essa foi uma abordagem expositiva, onde o professor explicou que na disciplina se teria a possibilidade de realização de uma análise semiótica, e, com ela, a escrita de um artigo científico com seus resultados, tendo esse, a possibilidade de publicação. Essa ideia foi bem aceita pelos estudantes e houve um comprometimento entre estudantes e professor de realizarem juntos o trabalho completo. Essa ação já contemplava um dos requisitos de aprendizagem ativa: a motivação-significativa para o estudante. A partir disso, solicitou-se, então, que os mesmos se organizassem em seis equipes, para iniciar o desenvolvimento das atividades.

A definição das equipes foi, também, por meio de proposta em um modelo de aprendizagem ativa. Essas deveriam se organizar por competências (modo profissional, multidisciplinar e de projeto). Foi possibilitado aos estudantes que se organizassem livremente, mas precisavam defender a equipe justificando as competências requeridas, para as quais preencheram uma ficha de competências, a qual, de acordo com Belbin (2016), deve ser julgada no final do processo.

Foi apresentado, também nessa aula, o que é a proposta da aprendizagem ativa, deixando claro aos estudantes quais são suas responsabilidades assumindo a aprendizagem baseada em projetos ( $\mathrm{PjBL}$ ), como atividade principal do semestre. A Figura 2 é um modelo do slide apresentado em aula para explicar a abordagem adotada. 


\section{RE ARTE \\ MODA \\ DESIGN}

| http://www.revistas.udesc.br/index.php/Ensinarmode

Figura 2: Representação de um processo de aprendizagem ativa.

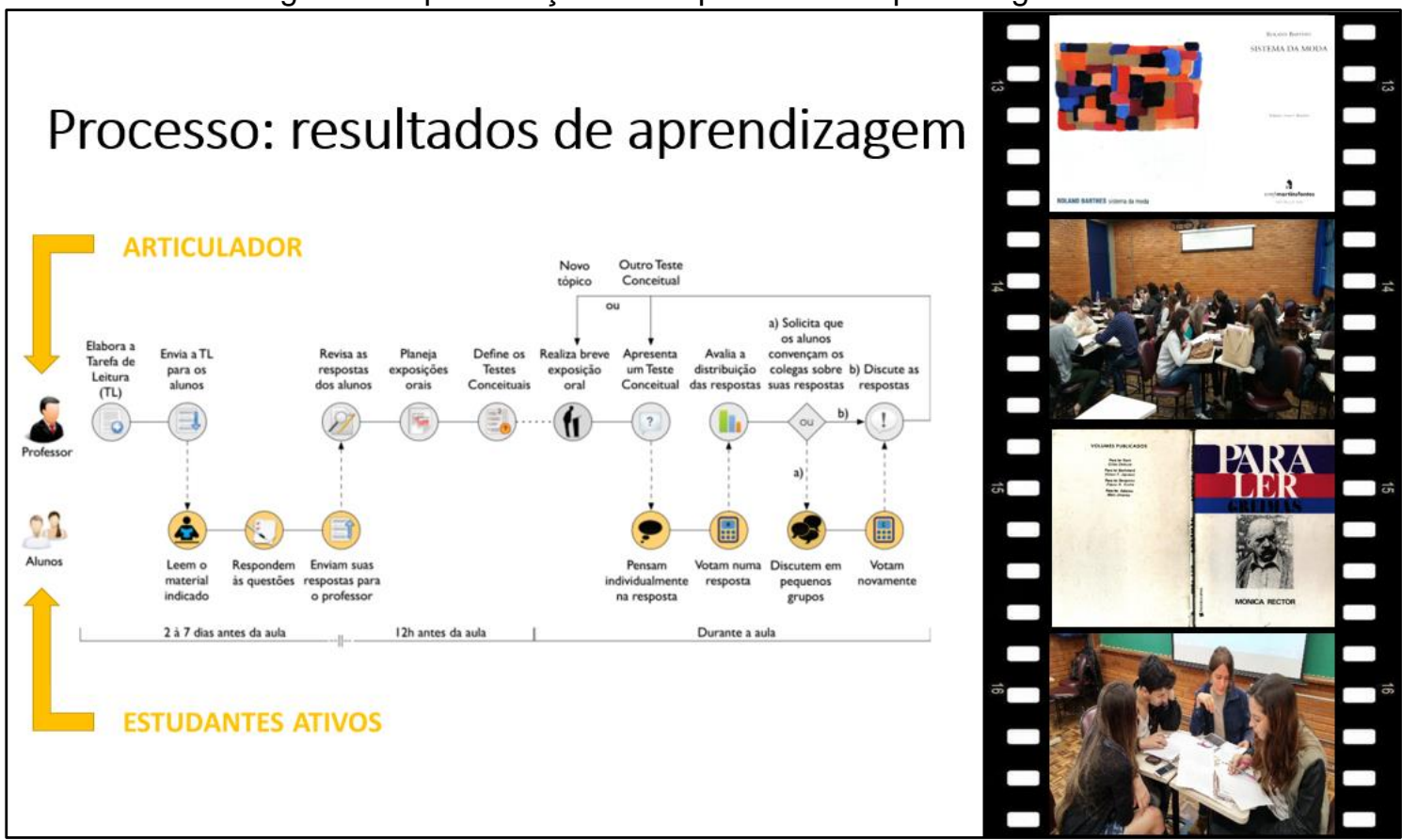

Fonte: A autora, com base em Mazur, 2016.

Foi colocado aos estudantes que, para um artigo, seria necessário fazer algo novo e desafiador, como por exemplo, a intenção de confrontar duas teorias semióticas em uma mesma análise. Nesse caso, conhecendo-se como expectativa da turma a ansiedade por aplicar a teoria greimasiana, comumente discutida na área de moda, o professor sugeriu o confronto da mesma com a metodologia peirciana, e essa proposta foi prontamente aceita pela turma.

Faltava apenas definir o produto a ser analisado. Assim, devida já à complexidade de se juntar essas duas teorias, a análise deveria ser testada em um produto com poucos elementos. Sugeriu-se aos estudantes trazerem para a aula seguinte, recortes imagéticos com propostas para escolha do tema.

Na segunda semana de aula, na Aula 2, já no primeiro horário da aula, foi realizado, como metodologia ativa, um brainstorming, apoiado com recortes de imagens de revistas de moda, para a definição do tema de pesquisa. Como condicionante, apenas, deveria ser escolhido um produto com elementos restritos para a análise, possibilitando, assim, maior foco em compor a análise completa. Cada equipe apresentou seu resultado e foi votada com unanimidade a análise sobre a publicidade de joias, definida em imagens publicitárias em revistas de moda. Pois estas, em geral, 


\section{RE ARTE \\ MODA \\ DESIGN}

apresentam de três a quatro elementos imagéticos: a joia, um personagem (geralmente uma mulher), um cenário e a marca.

Em equipes, no segundo horário da aula, foram planejadas as etapas do projeto escrever um artigo - para a qual, os estudantes elaboraram um Mapa Conceitual, contendo o seu entendimento inicial do que era necessário para iniciar a pesquisa. Esse mapa tinha a intenção de direcionar a estrutura sobre o tema, que é a metodologia para a pesquisa aplicada, definição do corpus de análise e resultados esperados. Isso permitiria, também, delinear um cronograma de acordo com as competências da equipe de projeto.

Com esses mapas, cada equipe apresentou sua proposta e, no quadro negro, o professor delineou o objetivo, que seria o mesmo para todas as equipes:

- Geral: analisar o poder da publicidade do design de joias.

- Específico: a) caracterizar o objeto de estudo em recortes de anúncios publicitários na revista Vogue (disponível na biblioteca da instituição), buscadas em suas edições atuais; b) dividir o objeto de estudo em duas tipologias - joias com ênfase no valor do material e joias com ênfase no valor de design (semi joia).

Durante a semana, as equipes deveriam enviar ao professor duas imagens de propostas para a análise.

Após essa definição, foi finalizado pelo professor o plano de ensino, o qual, por modelo da instituição, deve ser colocado em edital das disciplinas. O formato obtido seria apresentado na semana seguinte, e aplicado a partir da terceira aula. Esse plano, conforme exposto na Figura 3, além de conter o cronograma e conteúdo programático, foi construído de modo a apresentar também, de forma icônica, o papel ativo do estudante para a realização das atividades.

Figura 3: Planejamento da disciplina.

\begin{tabular}{|c|c|c|c|}
\hline & CONTEÚDO PROGRAMÁTICO & & TUDANTE \\
\hline \multirow{2}{*}{$\begin{array}{c}\text { AULA } \\
1\end{array}$} & $\begin{array}{l}\text { APRESENTAÇÃO plano de ensino / ementa / objetivos / procedimentos } \\
\text { didáticos / avaliação / normas / cronograma. PROPOSTA da } \\
\text { Aprendizagem baseada em Projeto: PjBL - Escrever um artigo científico. } \\
\text { TEMA: Semiótica Aplicada com o ensino de pesquisa Científica: Análise } \\
\text { Semiótica }\end{array}$ & & Foco \\
\hline & $\begin{array}{l}\text { DINÂMICA: definição das equipes ( } 6 \text { equipes de } 4 \text { alunos) por } \\
\text { competências (modo profissional, multidisciplinar e de projeto) - os } \\
\text { estudantes se organizam livremente, mas precisam defender a equipe } \\
\text { justificando as competências requeridas (ficha equipe) de acordo com } \\
\text { Belbin (2016) }\end{array}$ & & $\begin{array}{c}\text { Avaliação por } \\
\text { pares } \\
\text { (formativa) }\end{array}$ \\
\hline
\end{tabular}




\section{RE ARTE MODA DESIGN}

http://www.revistas.udesc.br/index.php/Ensinarmode

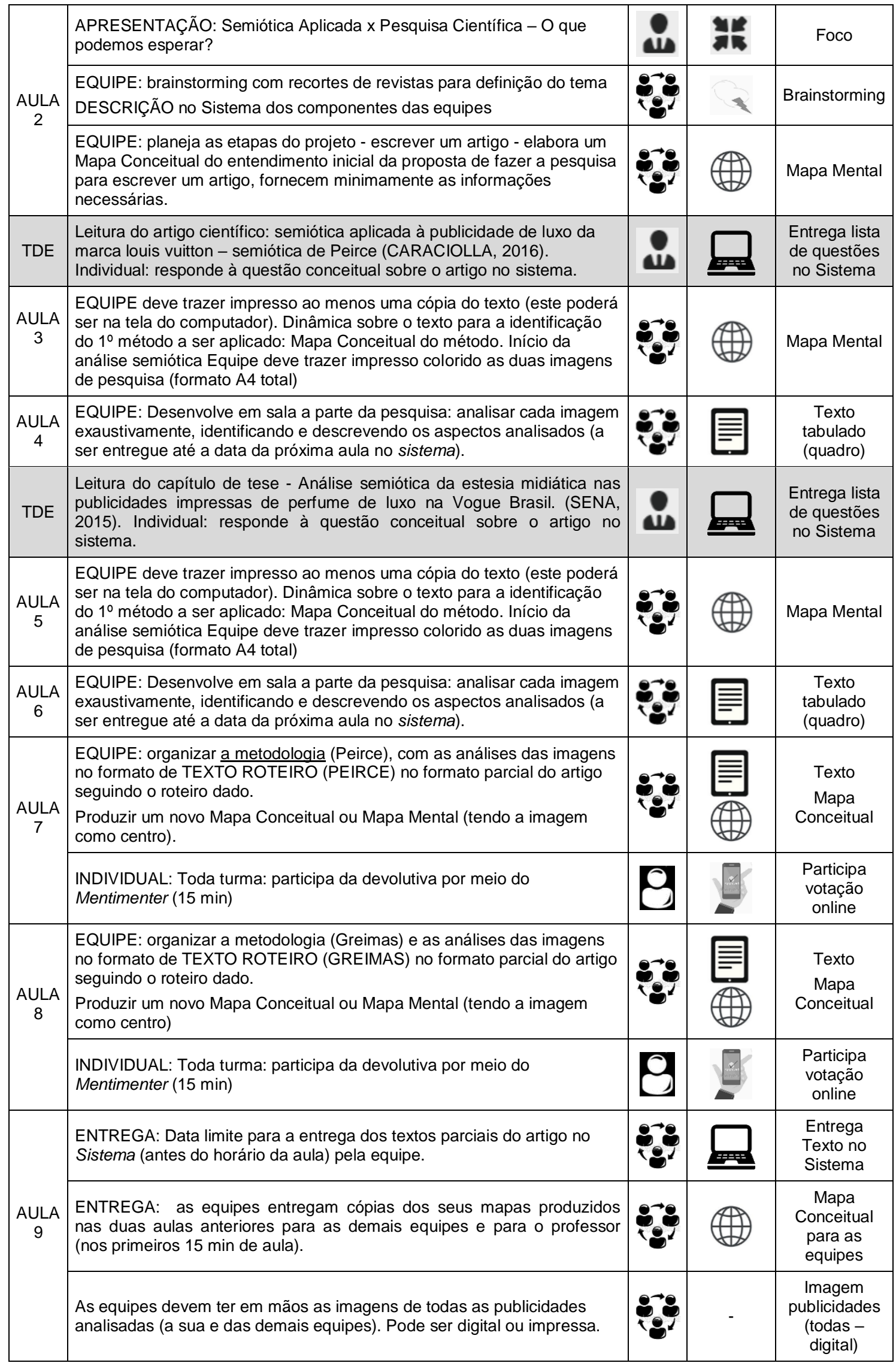




\section{RE ARTE MODA DESIGN}

http://www.revistas.udesc.br/index.php/Ensinarmode

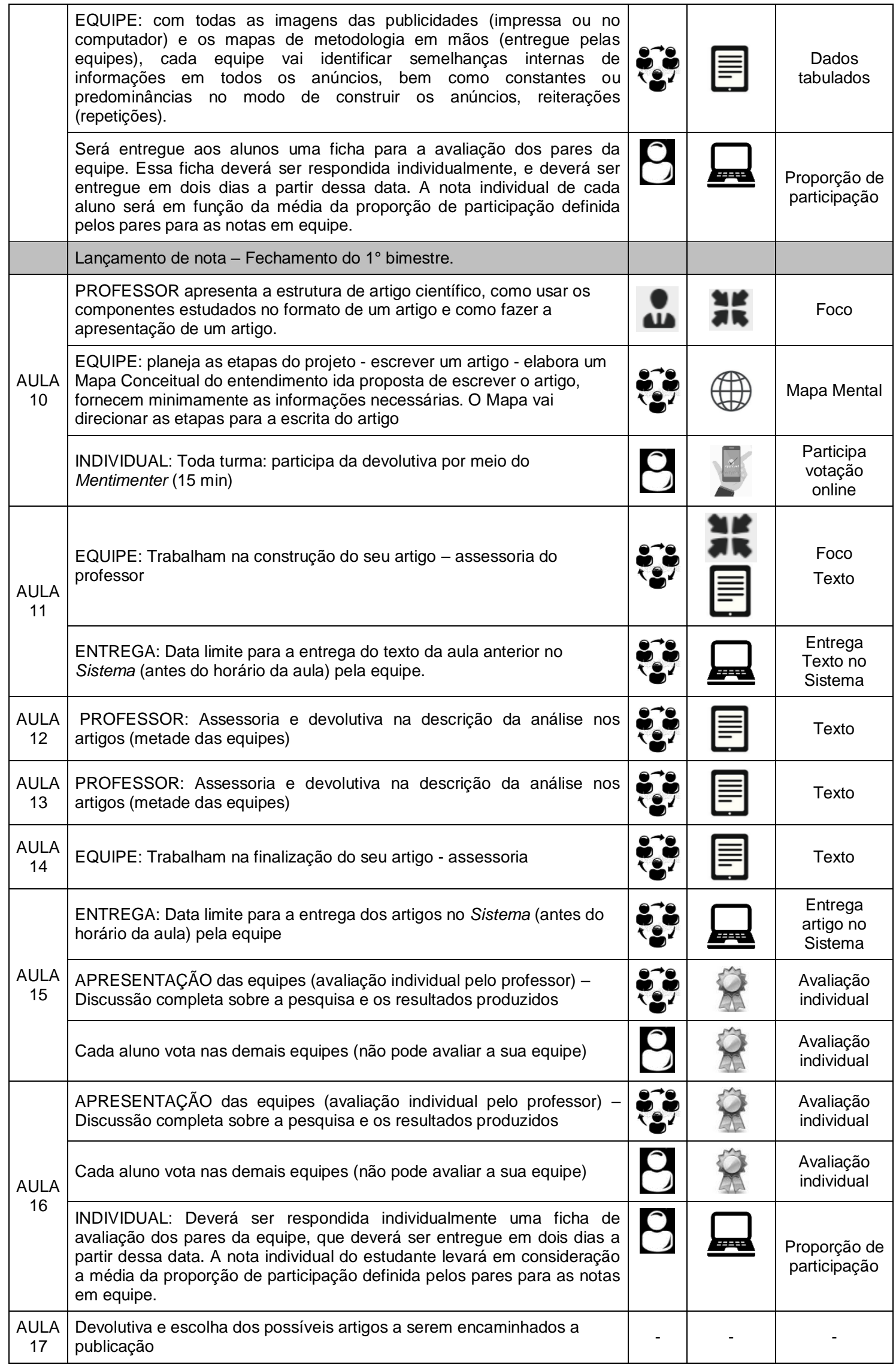




\section{RE ARTE \\ MODA \\ DESIGN}

| http://www.revistas.udesc.br/index.php/Ensinarmode

Lançamento de nota - Fechamento do $2^{\circ}$ bimestre.

Fonte: A Autora.

As atividades expostas no plano da disciplina, apresentado na Figura 3, acima, denominadas de TDE (Trabalho Discente Efetivo), são utilizadas na instituição para a complementação do número de horas no semestre para a disciplina. Essas foram importantes para o modelo de aprendizagem por Flipped Class. Nessas, os estudantes deveriam realizar a leitura de um texto, e responder à uma questão conceitual, antes das aulas.

Antes de iniciar a Aula 3, pela resposta dos estudantes, escrita de modo conceitual, inserida pelos mesmos no sistema Blackboard, utilizado na instituição (PUCPR, 2017), o professor sabia que apenas dois estudantes não realizaram a atividade. Essa atividade prévia faria com que os estudantes viessem para a aula já com conhecimento do que seria trabalhado. A orientação, para essa aula, era que as equipes deveriam trazer impresso uma cópia do texto ou tê-lo na tela do computador. A dinâmica sobre o texto seria a identificação da primeira metodologia a ser aplicada e apresentada em um Mapa Conceitual para descrever o método. Na sequência, as equipes já poderiam iniciar a análise semiótica com as imagens obtidas.

A primeira metodologia de análise semiótica proposta foi a abordagem de Peirce, que trata da significação dos signos. Um roteiro conceitual para a análise foi construído com essa metodologia pelas equipes, tendo como base a análise apresentada no artigo de Caraciola (2016). Sob a ótica dessa metodologia, a análise deve se iniciar pelo ponto de vista qualitativo - icônico. Nesse nível de interpretação se identificam as primeiras impressões dos signos. Na sequência, dentro de um processo de pensamento, têm-se os aspectos do ponto de vista singular - indicativo. Por fim, em um terceiro nível, está o ponto de vista convencional - simbólico. Assim, com base nesse modelo, as equipes descreveram sobre a metodologia e o resultado da análise realizada com as imagens.

Como o período que contempla a aula semanal é de duas horas/aulas, ou seja, de 1 hora e 30 minutos, muitas das atividades necessitam de mais tempo para completar a atividade presencial. Assim, na Aula 4 os estudantes completaram essa primeira análise.

Na Aula 5, foi iniciado o estudo com a segunda metodologia de análise, a da escola Francesa, que segue a abordagem de Greimas, tratando do discurso gerativo do 


\section{RE ARTE \\ MODA \\ DESIGN}

sentido. Os estudantes construíram novamente um roteiro conceitual para essa metodologia, com base na leitura e análise realizada em Sena (2015).

Na Aula 6 os estudantes completaram a segunda análise.

Nas Aula 7 e Aula 8, os estudantes reavaliaram seus mapas conceituais, reorganizaram as metodologias e as análises das imagens. Esse material deveria ser entregue ao professor, para o qual foi solicitado sua escrita mediante um template, de modo a facilitar a devolutiva para todas as equipes segundo as mesmas rubricas.

Nessas aulas, primeiramente foi realizada uma discussão sobre os temas, com questões norteadoras por meio do uso do Mentimeter (2017). Na sequência o professor apresentou uma devolutiva sobre as metodologias. A Figura 4 apresenta um mapa conceitual sobre a metodologia de Greimas, utilizado pelo professor para discussão sobre essa devolutiva.

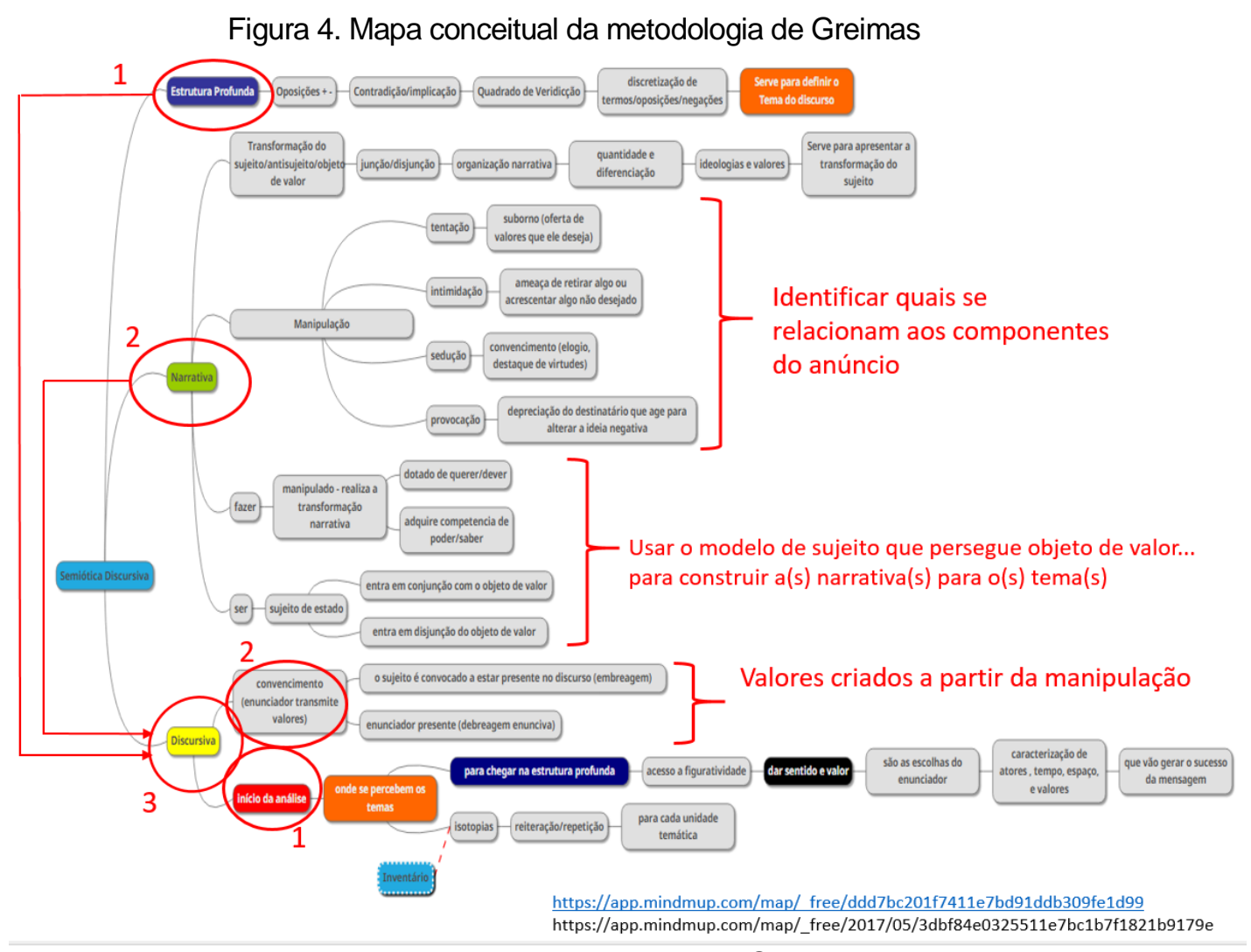

Fonte: A Autora, com base em Sena, 2015.

Na sequência das aulas, particularmente na Aula 9, os estudantes fizeram trocas entre os seus dados obtidos entre as demais equipes, de modo que identificassem 


\section{RE ARTE \\ MODA \\ DESIGN \\ | http://www.revistas.udesc.br/index.php/Ensinarmode}

semelhanças e diferenças, e poderem fazer assim, complementações sobre as suas próprias análises.

Para esse procedimento, nos primeiros 15 minutos de aula, as equipes entregaram cópias dos seus mapas produzidos nas aulas anteriores para as demais equipes e para o professor. Tendo em mãos, as imagens de todas as publicidades analisadas (a da sua equipe e das demais), cada equipe identificou semelhanças internas de informações em todos os anúncios, bem como constantes ou predominâncias e reiterações ou repetições, no modo de construção dos anúncios.

Nessa mesma aula foi entregue aos alunos uma ficha para a avaliação dos seus pares na equipe. Essa ficha deveria ser respondida individualmente, e entregue (em um determinado período de tempo) a partir dessa data. A nota individual de cada aluno seria afetada em função da média da proporção de participação definida pelos pares para as notas em equipe.

Todas as atividades realizadas, individuais e em equipes, geraram notas para a avaliação dos estudantes, que nesse período de tempo constituía o primeiro bimestre letivo.

No segundo bimestre, as aulas seguiram de acordo com o cronograma apresentado. Assim para a Aula 10, o professor apresentou a estrutura de artigo científico, o seu formato, e, como deveriam ser usados nele todos os componentes estudados e os resultados obtidos.

A partir disso, as equipes planejaram essas etapas em forma de um projeto, que era escrever um artigo. Essa atividade iniciou-se por meio da elaboração de um Mapa Conceitual, apresentando o entendimento da proposta e, fornecendo minimamente, as informações necessárias para direcionar as etapas referentes a escrita do artigo.

Nas aulas seguintes, da Aula 11 a Aula 14, os estudantes trabalharam na montagem e escrita do artigo. Durante o horário presencial na aula, o professor se revezava fazendo assessorias as equipes. E, assim, foram sendo escritos os artigos.

Nas Aula 15 e Aula 16, cada equipe fez a apresentação oral de seu trabalho e na Aula 17 foi realizada a finalização da disciplina por parte do professor e dado o feedback aos estudantes. 


\title{
RE ARTE \\ MODA \\ DESIGN \\ | http://www.revistas.udesc.br/index.php/Ensinarmode
}

\subsection{Devolutivas dadas aos estudantes sobre seus artigos}

Apresentam-se aqui, de modo genérico, exemplos das devolutivas dadas aos estudantes em suas equipes, tais como revisões e recomendações para possíveis envios dos artigos realizados para publicações.

Um exemplo de feedback dado, via sistema Blackboard, aos estudantes da equipe 1, foi o seguinte texto:

\begin{abstract}
O trabalho está bem apresentado e bem estruturado, possuindo melhorias a partir da versão anterior. Aplica corretamente a metodologia a partir dos dois textos estudados. No entanto, para publicação como artigo científico, ainda falta melhorar no embasamento teórico, a partir de autores conceituados da área. Pode-se referenciar os textos pelas metodologias utilizadas, mas os conceitos semióticos não são dos mesmos. Faltam referências. Falta, também, uma conclusão, que ainda é diferente da discussão. A conclusão responderia ao problema inicial, que era, na disciplina, em aplicar esse projeto de ensino.
\end{abstract}

Do mesmo modo, para a equipe 2 :

O trabalho está bem apresentado e atinge o objetivo da disciplina. No entanto, como artigo científico, após a introdução da referência sobre semiótica, falta explicar como a metodologia foi aplicada, para então virem os resultados da análise, depois uma discussão dos resultados e por fim uma conclusão. As chamadas das referências no meio do texto estão ainda incorretas. Falta a referência da revista.

Para a equipe 3 , a devolutiva resultou em:

O trabalho está bem apresentado e cumpre os requisitos da disciplina. No entanto, para ser um artigo passível de publicação falta força nas referências conceituais. Falta também a referência da própria revista. $\mathrm{O}$ trabalho apresenta um bom nível de discussão, como apresentado na devolutiva anterior. É um trabalho que atingiu as expectativas da disciplina, no entanto, para ser passível de publicação necessita de aprofundamento na escrita. Algumas frases apresentam linguagem coloquial, que não poderiam aparecer em um artigo.

Do mesmo modo, para a equipe 4:

Apresenta um bom trabalho. Atende os requisitos da disciplina. No entanto, ainda não é passível de publicação, pois apresenta alguns erros conceituais. A teoria de Greimas é apresentada como uma sequência de tópicos, sem mostrar a relação entre os mesmos. Na sua aplicação, os componentes de análise são descritos sem relacionar com os tópicos da teoria. Nas referências, falta a da própria revista. O texto do trabalho está em um nível de melhor qualidade do que a apresentação realizada, 


\section{RE ARTE \\ MODA \\ DESIGN}

| http://www.revistas.udesc.br/index.php/Ensinarmode

justificando e validando a aprendizagem. A teoria de Greimas é apresentada, no entanto sua aplicação na análise foi um tanto breve. Poderia ter gerado uma narrativa e discurso mais detalhado. Faltam algumas das referências utilizadas.

As descrições das devolutivas acima visam demonstrar a profundidade das abordagens realizadas pelos estudantes em seus trabalhos realizados em aula.

\section{CONSIDERAÇÕES FINAIS}

O conjunto de aulas apresentado foi realizado utilizando-se várias metodologias de aprendizagem ativa, sendo o PjBL - Project-Based Learning (aprendizagem baseada em projeto) a metodologia principal. No entanto, foram fundamentais o Flipped classroom (sala de aula invertida), para leitura dos estudantes fora da sala de aula e respostas às questões norteadoras que desencadearam as discussões realizadas em sala de aula. Do mesmo modo, a confecção de Mapa Conceitual e o uso do MENTIMETER (Interactive presentation software) auxiliaram nas dinâmicas aplicadas. Todas essas abordagens diferenciaram as aulas do modo tradicional, pois colocaram os estudantes em posição mais ativa, reflexiva, aprendendo com os pares e contextualizados em uma situação real, embora o que se chama de tradicional no design, já envolva atividades desenvolvidas para a reflexão.

Algumas aulas partiram da experimentação prática, realizada pelos estudantes, desenvolvidas a partir de material pontualmente disponibilizado pelo professor. Isso ocorreu porque, os estudantes poderiam demandar mais tempo tentando descobrir, por exemplo, qual seria a melhor referência a utilizar para o objetivo proposto: confrontar duas metodologias.

Embora sabendo que em uma proposta de aprendizagem ativa o método deve induzir ao uso do tempo de aula à reflexão dos estudantes, e entre seus pares, observa-se que, em muitos momentos, tem-se "guiado" os estudantes aos resultados de aprendizagem esperados, principalmente, devido ao tempo necessário. Como por exemplo, no que concerne ao tema principal desta etapa da disciplina - a aplicação da semiótica, não foi solicitado aos estudantes pesquisarem e definirem sobre quais as metodologias seriam melhores aplicadas. Isto teria feito 


\section{RE ARTE \\ MODA \\ DESIGN}

com que eles construíssem, de algum modo, um conhecimento prévio sobre o assunto.

Contudo, observa-se que a construção dessa abordagem para a disciplina, de um modo misto entre o intuitivo e o referenciado para aprendizagem ativa, proporcionou aos estudantes um excelente aprendizado. Houve um engajamento durante as aulas e a realização plena das atividades propostas. E, ao final, nas apresentações, após as devolutivas, os estudantes mostraram uma discussão com qualidade mais elevada do que haviam inicialmente escrito em seus textos. Isso mostrou um grande interesse na aprendizagem.

Considera-se que essa abordagem possa representar um avanço e inovação para disciplinas de semiótica aplicada. Há na literatura, propostas de uso de metodologias ativas, no entanto, nenhuma semelhante às atividades relacionadas na aplicação desta disciplina. Desse modo, acredita-se que essa prática metodológica possa avançar, além da confecção de um artigo científico, onde se discute sobre a prática da aprendizagem ativa, para novos meios de utilizá-la no ensino de semiótica.

Há, ainda, a necessidade de encontrar o equilíbrio no uso das técnicas de aprendizagem ativa. Tais como, compreender a relação entre o tempo de duração da aula, o tempo disponível do estudante fora da sala de aula, e a constância da aplicação de técnicas para efetivar o pensamento do estudante em modo ativo. Pois, pode-se observar que as pessoas têm tempos e modos de aprendizagem diferentes, e, às vezes, o uso de uma metodologia ou outra, pode acabar não ajudando no desempenho de uma tarefa.

Quanto à produção de um artigo científico, considera-se que os estudantes tiveram a experimentação completa das fases de sua realização. Isto é, desde a formulação do problema de pesquisa, a análise dos dados, a escrita do artigo e a devolutiva do professor, na forma de um revisor. Quanto à sua finalização e possível envio para publicação, não houve tempo durante o semestre de realização da disciplina.

\section{REFERÊNCIAS}




\section{RE ARTE \\ MODA \\ DESIGN}

BELBIN. Belbin Team Roles. Disponível em: <http://www.belbin.com/about/belbin-team-roles/ >. Acesso em: 15 fev. 2017.

BEHRENS, M. A. O paradigma emergente e a prática pedagógica. 5. ed. Petrópolis: Vozes. 2011.

BROCKBANK, A., MCGILL, I., BEECH, N. Reflective Learning in Pratice. 2002. Disponível em: $<$ https://books.google.com.br/books?id=QEy--3zRO1cC\&redir_esc=y> Acesso em 14 dez. 2015.

CARACIOLA, C. B. Semiótica aplicada à publicidade de luxo da marca Louis Vuitton.

Disponível em: <http://www.coloquiomoda.com.br/anais/anais/12-Coloquio-de->. Acesso em: 10 de mar. 2017.

CREARE. Oficinas de Metodologias Ativas. Curso de Formação Docente. Curitiba: PUCPR, 2015.

FELDER, R. M.; BRENT, R. Active learning: an introduction. ASQ Higher Education Brief. 2009. Disponível em:

<http://www4.ncsu.edu/unity/lockers/users/f/felder/public/Papers/ALpaper(ASQ).pdf> Acesso em 14 dez. 2015.

HAMDAN, N. et al. A review of flipped learning. 2013. Disponível em:

$<\mathrm{http}: / /$ researchnetwork.pearson.com/wp-

content/uploads/LitReview_2014_FlippedLearning_vFinal_JK_WEB.pdf> Acesso em $14 \mathrm{dez}$. 2015.

KOPP, V. et al. Self-Regulated Learning with Case-Based Worked Examples: Effects of

Errors. Evaluation \& Research in Education, v22 n2-4 p107-119. 2009. Disponível em: < http://eric.ed.gov/?id=EJ870883> Acesso em 14 dez. 2015.

LAKATOS, E. M.; MARCONI, M. A. Metodologia científica. 6. ed., rev. e ampl. São Paulo: Atlas, 2011.

LOU, S. et al. Construction of a Creative Instructional Design Model Using Blended, Project-Based Learning for College Students. Creative Education Vol.3, No.7, 1281-1290. 2012. Disponível em:<http://www.scirp.org/journal/articles.aspx?searchCode=ShiJer+Lou\&searchField=authors\&page=1> Acesso em 14 dez. 2015.

MAZUR, E. Peer Instruction: Getting Students to Think in Class. 1997. Disponível em: $<$ http://mazur.harvard.edu/sentFiles/Mazur_274537.pdf> Acesso em 14 dez. 2015.

MENTIMETER. Interactive presentation software. Disponível em: <https://www.govote.com>. Acesso em: 10 mar. 2017.

MITRE, S. M. et al. Metodologias ativas de ensino-aprendizagem na formação profissional em saúde: debates atuais. Ciência e Saúde Coletiva, Rio de Janeiro, v. 13. 2008. Disponível em: $<$ http://www.scielo.br/scielo.php?pid=S1413-81232008000900018\&script=sci_abstract\&tlng=pt > . Acesso em 14 dez. 2015.

PANITZ, T. Collaborative versus Cooperative Learning: A Comparison of the Two Concepts Which Will Help Us Understand the Underlying Nature of Interactive Learning. ERIC Collection. 2009. Disponível em: <http://files.eric.ed.gov/fulltext/ED448443.pdf> Acesso em 14 dez. 2015. 


\section{RE ARTE MODA DESIGN \\ | http://www.revistas.udesc.br/index.php/Ensinarmode}

PUCPR. Pontifícia Universidade Católica do Paraná. Disponível em: <http://pucpr.br/> Acesso em: 23 ago. 2017.

SCALLON, G. Avaliação da aprendizagem numa abordagem por competências. Trad. Juliana Vermelho Martins. Curitiba: PUCPress, 2015. 445 p.

SENA, T. V. Análise semiótica da estesia midiática nas publicidades impressas de perfume de luxo na Vogue Brasil. 2015. 262 f. Tese (Doutorado em Comunicação) - Pontifícia Universidade Católica de São Paulo, São Paulo, 2015. Disponível em: <https://sapientia.pucsp.br/handle/handle/4753>. Acesso em: 02 de mai. 2017. 